\title{
LABORATORY ANIMAL ANAESTHESIA
}

\author{
A.J.C. Holland, M.B.B.S., F.F.A.R.C.S., D.C.H.
}

\author{
"Twould ring the bells of Heaven, \\ The wildest peal for years, \\ If Parson lost his senses, \\ And people came to theirs, \\ And he and they together, \\ Knelt down with angry prayers, \\ For tamed and shabby tigers, \\ And dancing dogs and bears, \\ And wretched blind pit ponies, \\ And little hunted hares".
}

When Ralph Hodgson wrote "The Bells of Heaven" he did not have veterinary anaesthesia in mind. But it is an appropriate quotation as in most centres the standards of anaesthesia that animals receive, even though administered with the animal's welfare at heart, often fall far short of desirable both with regards to humanity and technical and scientific expertise.

The relatively low standard of veterinary anaesthesia practised, together with the wide variety of animals which are now being anaesthetized in laboratories and veterinary hospitals have prompted the writing of this article. Much that will be written reflects the author's own experience, and it is to be hoped that enough information will be imparted to anaesthetize safely most laboratory animals; at the same time some of the many anatomical, physiological and biochemical differences between various species of animals and man will be pointed out.

Vertebrate animals (and perhaps some invertebrate too) have similar pain pathways and similar perceptions of pain as man - their lack of ability to communicate does not indicate a lack of awareness of pain and does not condone inhumane treatment. Indeed, in the 1850s, G.H. Dadd, an American physician turned veterinarian, was routinely using general anaesthesia for animals long before it was readily available to humans. ${ }^{1}$

General or local anaesthesia will eliminate, if properly conducted, the pain of a surgical procedure, but appropriate techniques for the species of animal to be anaesthetized must be chosen, and the drugs employed must ensure the animal's survival if this is desired. Every anaesthetic is a form of physiological trespass, and the anaesthetist must always consider the effects his drugs will produce on body homeostasis. For example, chloralose augments the effects of nicotine on the animal's blood pressure, while barbiturates reduce it; ${ }^{2}$ essential fatty acid deficiency renders rats more liable to die during ether anaesthesia, but pentobarbitone can protect them. ${ }^{3}$

Most unnecessary deaths occur because of failure to maintain an adequate air-

Department of Anaesthesia, Montreal General Hospital. 
way. This is particularly true of small animals such as rats and rabbits, and careful positioning or intubation is mandatory to maintain a clear airway in all veterinary anaesthesia.

Body temperature may show a rise (e.g. a heavily furred animal anaesthetized in a hot room) or a fall. Body temperatures may affect the action of some drugs and it is obvious that the results of some experiments will be meaningless if the animal has an inadequate ventilation with carbon dioxide accumulation, an uncontrolled fall in body temperature, an inappropriate anaesthetic, and is dehydrated and short of essential fatty acids.

\section{Premedication}

As with human beings, any animal anaesthetic starts with a pre-operative assessment. This will include a history obtained from the animal's attendant, together with a physical examination. Acquired heart disease is not uncommon, while many animals are susceptible to respiratory infections. Chronic renal disease is common in dogs ${ }^{4}$ whose hydration will therefore have to be carefully watched.

While examining the animal, it will also be possible to form some opinion of the animal's temperament.

Most laboratory animals are docile, but it is a kindness to those which are nervous or aggressive to have them well sedated prior to the induction of anaesthesia.

Atropine, hyoscine, sedatives, tranquillizers and analgesics all have a place in premedication.

Atropine itself has a different metabolism in different animal species. The cat, rat and rabbit can hydrolyze large quantities of atropine through the presence of esterases in the kidney and liver. In other species, however, part of the atropine is excreted unchanged, part as tropine, and the fate of the remainder is unknown. The effects of atropine on the animal are essentially the same as in man, and the doses used tend to be somewhat arbitrary. For cats a dose of $0.3 \mathrm{mg}$ is ample, while for pigs and dogs, $0.3 \mathrm{mg}$ to $2 \mathrm{mg}$, depending on the size of the animal, is sufficient. As far as ruminants are concerned, salivation is always a problem, and although some authorities are reluctant to use atropine because of the increased viscidity of secretions, they are in fact best controlled by a premedicant dose of 10-15 $\mathrm{mg}$ of atropine ( $1 \mathrm{mg}-2 \mathrm{mg} / 3 \mathrm{Kg}$ body weight).

In animals, except the dog, hyoscine may produce considerable excitement, and is not a useful premedicant drug.

Morphia and other opiate analgesics can be used with safety in most animals. As in man, morphia will produce euphoria in the presence of pain, as well as having a sedative and calming effect; on the other hand it may produce discomfort and fear in the normal animal to the extent of "maniacal excitement" when given to the cat. $^{5}$ But even in the cat it may be used in small doses $(0.1 \mathrm{mg} / \mathrm{Kg}$ body weight $)$ while dogs may be given up to $10 \mathrm{mg}$, pigs $20 \mathrm{mg}$, and cattle $60 \mathrm{mg}$.

Other opiates can be used in equivalent doses, and techniques of neuroleptanaelgesia can be used equally well in animals as in man.

Ataractic drugs are widely used to provide sedation in laboratory animals. The phenothiazines and butyrophenones are the most frequently used drugs, and 
certain of these, such as chlorpromazine, can also be used with advantage in techniques involving controlled hypotension or hypothermia. Chlorpromazine is indeed a very useful premedicant drug in pigs, dogs and cats, each of which tolerate doses of $2-4 \mathrm{mg} / \mathrm{Kg}$ body weight intramuscularly or intravenously.

\section{Conduction Anaesthesia in Animals}

Local anaesthesia - infiltration blocks, nerve blocks, epidurals and spinals - are widely used in veterinary anaesthesia. Their use in providing anaesthesia for laboratory animals is perhaps more limited, although dogs can have many surgical procedures performed upon them using regional blockade alone.

Tufvesson ${ }^{6}$ has described most of the commonly used techniques of regional anaesthesia used in veterinary practice. The techniques are essentially similar to those employed in human patients, provided, of course, one remembers the differences in anatomy between the horse and the man! Docile laboratory animals such as the dog do very well under regional blockade, which is much more difficult, however, in less tractable animals such as the cat and the pig (a squealing, determined ball of muscle with a malevolent intelligence!). In field situations, local anaesthesia is used in animals such as horses and cattle which are often operated on in the standing position, which reduces the hazards of forcible casting and prolonged recumbency.

Epidural anaesthesia is a popular form of anaesthetic in moderate sized laboratory animals, cattle and horses. It is used in the main for lower abdominal operations, and operations around the perineum, vulva, and tail. The spinal cord of most quadrupeds ends at the lower lumbar region (that of the cow ending in the midsacral region) and the technique is to locate the lumbo-sacral space which can be found by palpating the two iliac crests; a line which joins them will cross the spinous process of the last lumbar vertebra immediately caudal to which one can palpate the depression of the lumbo-sacral space. For dogs, the needle employed must be up to $5 \mathrm{~cm}$ long, for pigs an 8 to $12 \mathrm{~cm}$ Tuohy needle is satisfactory, while cattle require a $20 \mathrm{~cm}$ needle. Because of their temperament pigs should be well sedated, while the anaesthetist who contemplates regional anaesthesia in a young and frisky colt should have a steady hand and be quick on his feet in order to avoid vigorous objection if the animal should resent being speared with a needle.

\section{General Anaesthesia for Laboratory Animals - General Considerations?}

This is the most common method of rendering animals unresponsive to the trauma of surgery, and, in most departments of experimental surgery it is carried out very badly. The tradition of an unconscious animal being unresponsive to noxious stimuli dies hard, and it is still a common experience to see animals rendered unconscious with a barbiturate, and then left to breathe (usually inadequately) room air for the duration of the surgical procedure. As already mentioned, the pain perception of an animal is similar to that of a human and its anaesthetic should be managed with similar care.

As with human subjects, general anaesthesia can be induced by intravenous or 
inhalational methods. The intraperitoneal route is often employed in those animals with poor veins.

The barbiturates, given intravenously, are the most commonly employed induction agents and pentobarbitone in a 6.5 per cent solution is most widely used. It can be given to dogs and cats in a dose of 25 to $30 \mathrm{mg} / \mathrm{Kg}$ body weight, or it can be used intraperitoneally in a similar dose. Recovery from pentobarbitone anaesthesia is prolonged (6-18 hours) and the animal may have to be restrained during that period. Although it is often used as the sole anaesthetic agent in veterinary practice, this is not a recommended method of anaesthesia and it should always be used in conjunction with an analgesic and added oxygen, with particular emphasis being placed on the maintenance of a clear airway.

Thiopentone is not used as widely in veterinary anaesthesia as one would expect. It is generally employed in a dose range of 25 to $30 \mathrm{mg} / \mathrm{Kg}$ body weight when anaesthetizing dogs and cats, and most dogs will tolerate tracheal intubation after thiopentone alone has been given.

Non-barbiturate drugs are also frequently used. Urethane (a carbonic acid ester of ethanol) has been used especially by the intra-peritoneal route. It can be used to anaesthetize frogs, by sprinkling the dry powder onto the frog's moist skin and washing off the excess when the desired level of narcosis has been reached.

A more commonly used drug, especially in England and Europe, is chloralose, which appears to lack the carcinogenic properties of urethane. It will produce light anaesthesia for long durations (one hour or more) without protective reflexes being greatly obtunded. ${ }^{8}$

Ketamine and phencyclidine have been used in veterinary anaesthesia reasonably extensively. The author uses ketamine in a dose of $3-6 \mathrm{mg} / \mathrm{Kg}$ body weight as his routine induction agent for anaesthetizing dogs and has had good results; Seal and Erickson" have used a phencyclidine-promazine mixture for the immobilization of large carnivora, with success in all except the tiger and the polar bear.

Anaesthesia can be maintained with any of the conventional gases and volatile agents. Halothane, probably the best studied of all anaesthetic agents, is used frequently for small animal anaesthesia. Adequate muscle relaxation for most intraabdominal surgery can be obtained with it alone.

If profound muscle relaxation is required in light planes of anaesthesia, muscle relaxants of either the depolarizing or non-depolarizing type can be used; succinyl choline can be of great use to facilitate intubation in the rabbit, cat, and pig, although for the latter two animals, the author prefers to use gallamine. For most animals, a paralyzing dose of succinyl-choline is $0.1 \mathrm{mg} / \mathrm{Kg}$ body weight (about one tenth the dose used in man) and in the dog such a dose will give prolonged relaxation.

Animals seem more susceptible than human subjects to the histamine release and ganglionic blockade effects of curare, and although curare can be used, it seems that gallamine is the non-depolarizing relaxant of choice; however, the newly introduced non-depolarizing relaxant, pancuronium, may prove to be even better. ${ }^{10,11}$ The non-depolarizing drugs will require normal (by human standards) doses of atropine and neostigmine to produce reversal, viz. atropine $0.02 \mathrm{mg} / \mathrm{Kg}$ body weight, neostigmine 0.02 to $0.05 \mathrm{mg} / \mathrm{Kg}$ body weight. 
With virtually all moderate to large-size laboratory animals, normal anaesthetic apparatus and ventilators can be used. Any departures from normal will be mentioned in the next section.

\section{General Anaesthesia - Special. Considerations}

Laboratory animals may range in size from a small mouse to a large baboon, and more and more exotic species are finding their way into the experimental laboratory. The anaesthetist involved in such work should therefore have some idea of normal respiratory and cardiac parameters of common experimental animals. Table I attempts to summarize them. ${ }^{12,13,14,15}$

With this general information, the anaesthetist is now well enough equipped to anaesthetize different species of animals and to alter his techniques appropriately to the size and nature of the animal with which he is dealing.

\section{The Dog}

The dog possesses a highly evolved central nervous system which responds to anaesthetic agents in a fashion similar to man. Data obtained from dog experiments can be fairly readily extrapolated to man, dogs are easily managed and are capable of displaying feelings of pain and pleasure.

The dog is easy to intubate and its upper airway mucosa is comparatively insensitive, enabling it to tolerate tracheal tubes and irritating gases. In general the $\operatorname{dog}$ is slightly more resistant to anaesthetic agents than the human, but cardiovascular and respiratory responses to anaesthesia are the same as in man.

Intravenous thiopentone $(15-25 \mathrm{mg} / \mathrm{Kg}$ or pentobarbitone $30 \mathrm{mg} / \mathrm{Kg}$ ) given slowly into the cephalic vein of the forelimb, followed by tracheal intubation, and maintenance with $\mathrm{N}_{2} \mathrm{O} / \mathrm{O}_{2}$ and halothane 1-2 per cent using a circle system has been found satisfactory in the author's experience. Succinyl-choline or gallamine will provide further relaxation if required and ventilation can be controlled using any standard anaesthetic respirator, or the Harvard pump.

Local anaesthesia can be employed in the dog and more exotic techniques of induced hypotension, hypothermia, and cardio-pulmonary bypass may be used provided that, as with the human patient, suitable monitoring is employed and resuscitation is not delayed if circulatory collapse should occur.

As with all animals, the post-anaesthetic stage is critical, and the animal should be carefully monitored from the point of view of body temperature, circulation, airway problems and injury from sharp objects, until full consciousness has been regained.

\section{Cats}

While not as docile as the dog, cats are none the less relatively inexpensive and reliable laboratory animals. They are susceptible to feline panleukopenia and pneumonitis, against which they must be vaccinated, and they should be fasted for 12 hours prior to operation (but water should only be withheld for 1 to 2 hours because they readily become dehydrated).

Most cats require premedication, which can be given subcutaneously into the tissues of the back of the neck. Pethidine $10 \mathrm{mg} / \mathrm{Kg}$ body weight, chlorpromazine 


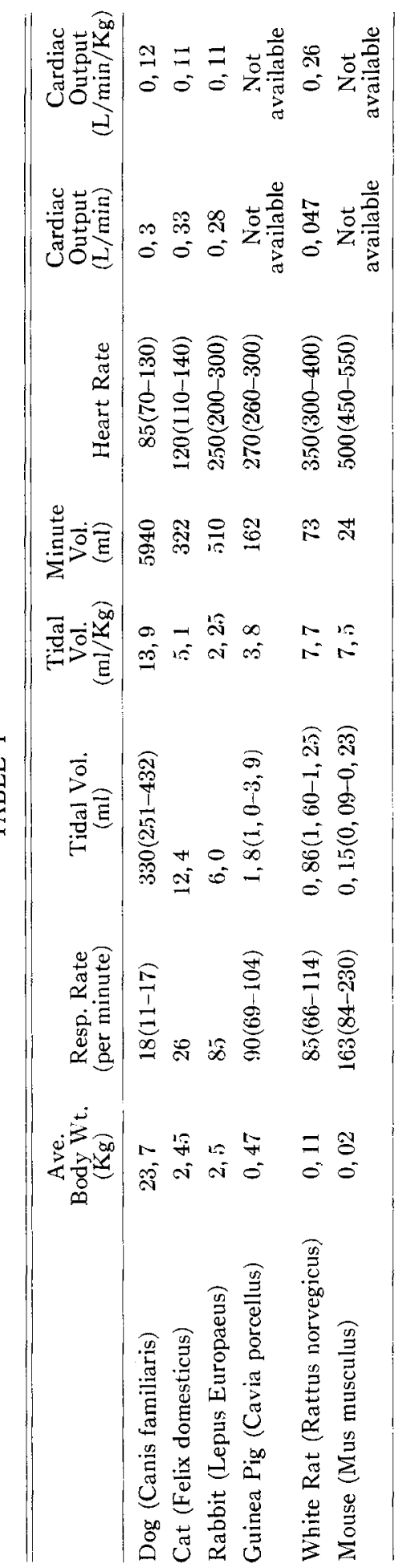


$2 \mathrm{mg} / \mathrm{Kg}$ body weight, and atropine $0.06 \mathrm{mg} / \mathrm{Kg}$ body weight is a safe and effective premedication.

Pentobarbitone and thiopentone intravenously or intraperitoneally are the most popular methods of induction. It should be noted that the cat has a slower rate of drug metabolism than the human, unlike other common laboratory animals. ${ }^{16}$

A stage of excitement is common in the cat and should be avoided if possible by premedication, careful handling, and tranquil surroundings. For maintenance (or inhalational induction) simple open drop, Magill, or Ayre's T-piece systems are best, in which rebreathing is prevented and yet the dead space is not unduly increased.

Tracheal intubation is not easy, but can be facilitated with halothane or succinyl choline $0.1 \mathrm{mg} / \mathrm{Kg}$ body weight. The laryngeal aditus can usually be seen, using a Macintosh curved blade, and the trachea can be intubated with a Cole endotracheal tube, 12 Fr or 14 Fr gauge.

Large cats such as the lion and tiger, can be anaesthetized in similar fashion, using a similar dose/weight drug schedule.

\section{Pigs}

The pig is becoming increasingly used as a laboratory animal, and in many instances its response to drugs and stressful situations resembles that of a human more closely than any other animal. Being powerful and independent creatures they should be well pre-medicated before anaesthesia is induced (atropine 0.1 $\mathrm{mg} / \mathrm{Kg}$, pethidine $2 \mathrm{mg} / \mathrm{Kg}$ and promazine $2 \mathrm{mg} / \mathrm{Kg}$ ) and atropine may have to be injected during the course of the operation to prevent excessive salivation. Thiopentone $(10-12 \mathrm{mg} / \mathrm{Kg})$ through a marginal ear vein is the induction agent of choice, and is followed by succinyl-choline ( 1 to $2 \mathrm{mg} / \mathrm{Kg}$ ) to facilitate the tracheal intubation which should be performed in all pigs because of the ease with which their respiratory centres become depressed following induction of anaesthesia and because of difficulty in otherwise maintaining a clear airway. Intubation is not easy, but can be done using a long straight blade laryngoscope and an introducer for the tube. $\mathrm{N}_{2} \mathrm{O} / \mathrm{O}_{2}$ and halothane provide excellent maintenance and non-depolarizing relaxants are rarely needed.

\section{Infrahuman Primates}

Infrahuman primates, being the species most closely related to man, are of particular interest to research workers. Unfortunately their limitations as regards cost, availability, ease of handling, and susceptibility to respiratory infections render them an uncommon experimental animal.

In spite of this, the literature on primates is voluminous and methods for their handling, restraint and anaesthesia have been well described. ${ }^{17,18}$

The strength and ferocity of adult baboons, chimpanzees, and gorillas are such that adequate pre-operative sedation is necessary. Even small primates can be vicious and unpredictable. Primates tolerate large doses of morphia (up to $3 \mathrm{mg}$ / $\mathrm{Kg}$ ), chlorpromazine in a similar dose, and atropine $(0.1 \mathrm{mg} / \mathrm{Kg})$. Occasionally the release from higher control by such a combination of drugs may produce a completely manic animal and therefore these animals must always be left in tranquil surroundings and handled slowly and carefully. 
Neuroleptanalgesia has been tried and so has phencyclidine,$^{19}$ which has been employed in a dose ranging from $0.25 \mathrm{mg} / \mathrm{Kg}$ in large primates to $3.0 \mathrm{mg} / \mathrm{Kg}$ in small species. It would seem that ketamine, a derivative of phencyclidine, which is already widely used in human anaesthesia, could well be a most useful drug both for premedication and the production of anaesthesia in the primate although dosages have yet to be established.

Primates should be restrained by a squeeze cage or by nets while injections are being made; smaller ones, which do not need such restraints, should be handled by experienced and careful attendants wearing protective gloves.

It would seem that conventional anaesthesia is satisfactory in primates. Thiopentone and pentobarbitone are the most commonly used induction agents in doses of $15-25 \mathrm{mg} / \mathrm{Kg}$ respectively. Anaesthesia can be maintained by any appropriate inhalational agent, while muscle relaxants can be employed in doses apparently similar to those required in man.

Regional anaesthesia, although satisfactory, is difficult to accomplish in a primate owing to the difficulty of handling these animals, and offers no advantage over general anaesthesia.

Little is known about effective anaesthetic techniques in the primate; their cost, their vicious nature and their comparative rarity are disadvantages which the advantage of their anatomical and physiological similarity to man cannot outweigh.

\section{Ruminants}

Of the ruminants the sheep is probably the most commonly used laboratory animal. The chief difficulties experienced with them are excessive salivation, tympanitis, and regurgitation from the rumen. The latter two can be eliminated to a great extent by fasting the animal, the former can be reduced by giving atropine in large doses $(0.5 \mathrm{mg}-0.7 \mathrm{mg} / \mathrm{Kg})$ and repeating it in doses of $0.2 \mathrm{mg}-0.3 \mathrm{mg} / \mathrm{Kg}$ every 15 to 30 minutes of the operation. Contrary to some authorities ${ }^{4}$ this has not, in the author's experience, produced excessive stickiness of salivary secretions. Thiopentone, in a dose of $20-25 \mathrm{mg} / \mathrm{Kg}$ through the jugular vein, is an excellent induction agent, after which intubation can easily be performed. The animal can be maintained on $\mathrm{N}_{2} / \mathrm{O}_{2}$, and halothane. For muscle relaxation the author has found gallamine $(1 \mathrm{mg} / \mathrm{Kg})$ to be useful and safe. In his experience sheep have been very susceptible to the histamine release and ganglion blocking actions of curare which has, however, been used in other ruminants quite safely by other authorities. ${ }^{19}$

\section{Rabbits}

Of all laboratory animals rabbits are the most difficult and unpredictable to anaesthetize, because of the wide variation in their dose requirements and because of the narrow margin between surgical anaesthesia and death.

Due to the widely differing susceptibility of rabbits to anaesthetic agents, it is almost impossible to give a reliable dose range of drugs. It is technically very difficult to intubate a rabbit, so that the airway is always a problem. But because its thoracic cavity is covered by a membrane extending from the pericardium to the sternum, it is useful in thoracic surgery because the mediastinum can be entered through a sternal splitting incision without producing a pneumothorax. 
Anaesthesia can be induced by the inhalation or intravenous routes. The marginal ear vein is best for intravenous induction, and thiopentone or pentobarbitone can be used. Both thiopentone and pentobarbitone should be used in dilute solution ( 1.25 per cent and 6 per cent respectively) and the estimated dose ( $50 \mathrm{mg} / \mathrm{Kg}$ and $30 \mathrm{mg} / \mathrm{Kg}$ ) should be injected slowly and in small increments; being prepared to wait several minutes for a maximal effect.

Inhalation anaesthesia can also be used for induction or maintenance, and ether and halothane are the two most widely employed agents. With both intravenous and inhalation anaesthesia, the rabbit should be maintained quiescent in a rabbit box (which closely resembles the stocks of the Middle Ages) and surgical anaesthesia is established when there is no response on pinching the skin between the toes of the paws.

As respiration is very easily depressed, it is wise in any prolonged procedure to perform a tracheostomy and to be prepared to assist or take over ventilation. Ventilators such as the Bourne or Amsterdam, designed for neonates, can be used, but an Ayre's T-piece together with an intermittently occluding thumb is cheaper and simpler.

\section{Rats, Guinea Pigs, Mice}

Most text books describe methods to anaesthetize these animals in rather a cursory fashion. In fact they are good experimental animals if handled gently and anaesthetized with care. They are susceptible to cold and lose body temperature rapidly if immobilized in a cold environment.

Probably the commonest method of induction is to use a bell jar divided into two compartments by a metal sieve. The animal to be anaesthetized is placed in the upper compartment, and cotton wool soaked in ether in the lower. Halothane, Chloroform or $\mathrm{CO}_{2}$ (administered by putting dry ice in the lower compartment) can also be used. Rats and mice can also be induced by intravenous barbiturates (injected into a tail vein) or by intraperitoneal barbiturates.

Once anaesthesia is induced, it can be maintained for long periods of time by using a nose cone or by intubation through a tracheostomy.

It is rarely that these animals need pre-anaesthetic drugs. In general they are anaesthetized only for short procedures and atropine, which they tolerate in high doses, is not required. They should be fasted for 12 hours prior to anaesthesia, and should always be handled quietly (they have efficient teeth and know how to use them!).

As with all animals, but markedly so with the rat, liver or kidney disease, starvation and concomitant illness may profoundly alter drug action. And female rats are much less able to metabolize certain drugs than are males. ${ }^{21}$

The animals easily develop respiratory failure and may be resuscitated by placing a rubber tube over their nostrils, and breathing rapidly into the other end. More spectacularly, but probably no more efficiently, the mouse can be resuscitated by ensuring that it has a clear airway by pulling the tongue out with forceps and then grasping it by the tail and swinging it around in a circle. ${ }^{22}$

\section{Birds}

Like their mammalian counterparts, birds should be handled carefully as mere 
physical restraint may produce shock in some species. Although not commonly used as laboratory animals, poultry birds have been used for tendon experiments. Their air sac system may render volatile agents dangerous, because of the ease with which an overdose can be produced, so that parenteral administration either intramuscularly or intravenously through the medial wing vein or jugular vein is the most commonly employed technique. Gandal ${ }^{23}$ advocates the use of intramuscular Equithisin, " a proprietary preparation containing chloral hydrate, pentobarbitone, and magnesium sulphate in an aqueous solution of propylene glycol and alcohol. The dose is $2.0-3.0 \mathrm{mg} / \mathrm{Kg}$ intramuscularly or about half this intravenously into a medial vein of the wing.

Larger birds, from duck size upwards, can in fact be reasonably easily intubated, but smaller birds require care and a good deal of ingenuity to maintain satisfactory inhalational anaesthesia.

\section{Fishes}

Wider use of anaesthesia for fishes for experimental as well as therapeutic procedures has only been in practice for a few years. ${ }^{24.25}$

Many agents have been used in an effort to combine adequate sedation with minimal changes in fish physiology, and the majority of agents used have been successful.

As a rule it is better to add the agent to the tank in which the fish is held, but the species of fish to be anaesthetized and the temperature and composition of the water must be considered. As a generalization the author would prefer to anaesthetize a minnow rather than a shark.

Compounds such as heavy alcohols, ether, urethane, chloral hydrate and triocane-methane-sulfonate have all been used safely, by the simple means of adding these substances to the water of the fish tank. Of these, tricane methanesulphonate in doses of $50-100 \mathrm{mg}$ per litre of water is probably the most popular, but it cannot be used in salt water or in direct sunlight.

Fish are fairly sensitive to anaesthetic agents, and the margin between anaesthesia (loss of reflex activity, loss of opercular movements) and death is not great. Rapid change in temperature and composition of the water may produce death.

At the plane of surgical anaesthesia the fish turns upside down, and opercular (respiratory) movements are markedly decreased. At this point a fish can be taken out of the tank and placed on a damp towel for 3-5 minutes, but if gasping respiratory efforts occur, it must be replaced in its tank of anaesthetic solution.

\section{Amphibians and Reptiles}

In spite of the low phylogenetic position of amphibians and reptiles, common humanity at the very least dictates that they should be anaesthetized prior to surgical procedures.

Frogs can be anaesthetized by placing them in an ether containing bell jar, by placing urethane on their skin, or by injecting 1-2 $\mathrm{ml}$ of 10 per cent chloral hydrate into the dorsal lymph sacs ${ }^{26}$ (paired heart-like organs situated adjacent to the last

\footnotetext{
"Equithisin

$500 \mathrm{ml}$ contains $21.3 \mathrm{~g}$ chloral hydrate; $4.8 \mathrm{~g}$ pentobarbitone; $10.6 \mathrm{~g} \mathrm{MgSO}_{4}$ in aqueous propylene glycol 35 per cent and $\mathrm{C}_{2} \mathrm{H}_{5} \mathrm{OH} 9.5$ per cent.
} 
vertebra). Intraperitoneal pentobarbitone ( $60 \mathrm{mg} / \mathrm{Kg}$ body weight) which gives many hours anaesthesia, and hypothermia have also been tried.

Little is known about reptilian anaesthesia. The author has used ether for anaesthetizing turtles (administered by a face cone), which can be augmented by hypothermia (simply putting them in a refrigerator). Probably halothane could be used, while barbiturates and urethane are sometimes employed.

Snakes have been anaesthetized by the author with hypothermia alone. More orthodox techniques have included intraperitoneal barbiturates, and inhalational anaesthesia, e.g. halothane, ether, and chloroform. ${ }^{27}$

Post-operatively snakes, as all poikilotherms, should be left moderately cool to reduce their metabolic needs and oxygen demands, and one should be prepared to assist ventilation by tracheal intubation if anaesthesia becomes overly deep, and the intercostal muscles (the only muscles of respiration) become paralysed.

Large reptiles, such as alligators can be heavily sedated with oral pentobarbitone, and then anaesthetized with intra-peritoneal pentobarbitone. Non-depolarizing muscle relaxants can also be used in conventional fashion.

\section{Invertebrates}

Lower organisms probably do not perceive pain in the sense that man does, but often anaesthetic techniques will have to be used in the laboratory to reduce mobility of multicellular organisms, and to facilitate mounting techniques. In general the signs of "anaesthesia" in such unicellular and multicellular organisms is cessation of motility.

For most phyla, the artificial habitat should resemble the natural one, and, as with invertebrates, sudden temperature changes can be fatal.

In most cases invertebrates can be anaesthetized by adding the appropriate agent to their water, or exposing them to an atmosphere containing the anaesthetic agent.

Chloretone, ether, tobacco smoke, chloral hydrate, carbon dioxide and ethylene are among the many agents that have been employed to anaesthetize a wide variety of invertebrate phyla. Probably the best review of invertebrate anaesthesia is to be found in the Proceedings of the Federation of American Societies for Experimental Biology.28

\section{CONCLUSION}

To most anaesthetists, the field of animal anaesthesia is completely unknown, while on the other hand, most veterinarians have not had the necessary formal training in physiology and pharmacology to assess their anaesthetic agents and techniques realistically. As a result of this there is often an unnecessarily high morbidity and mortality among experimental animals, and inadequate anaesthesia can well render many experimental results suspect.

It is rather regrettable that animal anaesthesia plays virtually no part in the post-graduate education of the anaesthetist. A great variety of animals are being used more and more frequently in departments of experimental Medicine and Surgery for research purposes - ordinary humanity dictates that they should receive the best possible anaesthetic for procedures which are often prolonged and painful.

This article has dealt with methods of anaesthetizing virtually all types of 
laboratory animals although the relative lack of readily available information concerning techniques of small animal anaesthesia together with the wide variety of animals being anaesthetized in laboratories and veterinary hospitals compounds the difficulty of choosing the most appropriate anaesthetic method.

IIl-judged and inadequate anaesthesia in the experimental animal can only increase post-operative morbidity and mortality; while the experiments performed under such conditions will have results of doubtful validity. Although this article is far from a universal compendium of veterinary anaesthetic techniques, it does reflect the author's own experience in most instances, and it has attempted to describe safe and humane anaesthetic techniques as well as indicating some of the many anatomical, physiological and biochemical differences between various animal species that make veterinary anaesthesia such a complex but fascinating problem.

\section{RÉSUMÉ}

On a décrit des méthodes en ce qui concerne l'anesthésic locale et générale chez les animaux expériment aux.

Beaucoup d'animaux sont employés en recherche, et c'est dommage que la plupart des anesthésistes ne connaissent rien au sujet d'anesthésie vétérinaire.

L'anesthésie inadéquate chez l'animal experimental augmente la morbidité et la mortalité post-opérative, et les recherches exécutées par une telle anesthésie ne sont pas toujours valables.

L'auteur a décrit ses expériences et il a essayé d'énumérer des techniques anesthétiques qui sont à la fois humaines et sûres. Il a souligné les différences anatomiques, physiologiques, et biochimiques entre les différentes espèces d'animaux, et il a plaidé pour un plus de connaissance et une plus grande intérêt en ce qui concerne l'anesthésie vétérinaire.

\section{ACKNOWLEDGMENTS}

My acknowledgments go to Dr. Peter Jackson, Anaesthetist at the Jewish General Hospital, who helped anaesthetize many of the animals described in this article; also to Mr. Andrew Mott and Miss Robin Jones both of the Department of Experimental Surgery at the Montreal General Hospital, without whose advice and encouragement this article would never have been written.

\section{REFERENCES}

1. DADD, G.H. The Modern House Doctor. Boston: J.R. Jarrett and Company (1854)

2. Chenoweth, M. \& VAN Dyke, R.A. Anaesthesia in biomedical research. Federation Proceedings 28: 1383 (1969).

3. CASTER, W.O. \& AKN, P. Electrocardiographic notching in rats deficient in essential fatty acids. Science 139: 1213 (1963).

4. Hall, L.W. "Wrights" Veterinary Anaesthesia and Analgesia. London, Bailleu, 7th ed. (1971).

5. Alexander, F. An Introduction to Veterinary Pharmacology. Edinburgh, Livingstone $(1960)$. 
6. Tufvesson, G. Local Anaesthesia in Veterinary Medicine. Livingstone, Sodertalje, AB Astra (1963).

7. Strobel, G.E. \& Wollman, H. Federation Proceedings 28: 1386-1403 (1969).

8. Bass, B.G. \& BuCKLEY, N.B. Chloralose anaesthesia in the dog: a study of actions and analytical methocology. Ass. J. Physiol. 210: 854 (1966).

9. SEAL, U.S. \& EnICKson, A.W. Federation Proceedings 28: 1410 (1969).

10. Bonta, I.L., Buckett, W.R., Lewis, J.J., \& VargaftiG, B.B. 2B, 16B Dipiperidono-5androstane 317 diol diacetate dimethobromide (NA97) a potent neuromuscular blocking steroid. Second International Congress on Steroids, Milan Abstracts, p. 344 ( 1966 ).

11. BUCKETT, W.R. The pharmacology of pancuronium bromide: a new non-depolarizing neuromuscular blocking agent. Irish Journal Med. Sc. Seventh Series 1: 12 (1968).

12. Guyton, A.C. Circulatory physiology: cardiac output and its regulation. Pennsylvania, Saunders (1963).

13. Natronal Research Councrl. Committee on the Handbook of Biological Data. Handbook of Circulation compiled by P.C. Altman. Pennsylvania, Saunders (1959).

14. Kleinman, L.I. \& Radford, E.P. JR. Ventilation standards for small mammals. J. Appl. Physiol. 19: 360 (1964).

15. National Research Council. Committee on the Handbook of Biological Data. Handbook of Respiration compiled by P.L. Altman. Pennsylvania, Saunders (1958).

16. Brodie, B.B. Of mice, microsomes, and man. Pharmacologist 6: 12 (1965).

17. Graham-Jones, O. (editor). Small Animal Anaesthesia. Oxford, Pergammon (1964).

18. Lumb, M.V. Small Animal Anaesthesia. Philadelphia, Lea and Febiger (1963).

19. Bryant, S.H. General anaesthesia in the goat. Federation Proceedings 28: 4 (1969).

20. Quin,, G.P., Axelrod, J., \& Brodie, B.B. Species, strain and sex differences in the metabolism of hexobarbitone, amidopyrine, antipyrine, and aniline. Biochem. Pharmacol. 1: 152 (1958).

21. Holck, H.G.O., Kanan, M.A., Mills, L.M., \& Smith, E.L. Studies upon the sex differences in rats in tolerance to certain barbiturates and to nicotine. J. Pharmacol. Exptl. Therap. 60: 323 (1937).

22. Croft, P.G. An introduction to the anaesthetics of laboratory animals. Universities Federation for Animal Welfare. London (1960).

23. Gandal, C.P. Satisfactory general anaesthesia in birds. J. Am. Vet. Med. Assoc. 128: $332(1956)$.

24. MCFARLAND, W.N. A study of the effects of anaesthesia on the behaviour and physiology of fishes. Public Inst. Marine Science 6: 23 (1959).

25. MCFArLaNd, W.N. The use of anaesthetics for the handling and transport of fishes. Calif. Fish Games 46: 467 (1960).

26. TANNER, J.T. Some useful demonstrations in teaching zoology. Turtox News 32: 2 (1954).

27. Brazenor, C.W. \& Kaye, G. Anaesthesia for reptiles. Copeia 3: 165 (1953).

28. Kaplan, H.M. Anaesthesia in invertebrates. Federation Proceedings 28: 4 (1969). 